\title{
Study on Improving Corrosion Resistance of Tantalum Coating by Anodic Oxidation
}

\author{
Jincheng Hou ${ }^{1}$, Yuan Wang ${ }^{1, *}$, Zhentao Yuan ${ }^{2, *}$, Hongzhong Cai ${ }^{3, *}$, Wengang Chen ${ }^{1}$ \\ ${ }^{1}$ School of Machinery and Communications, Southwest Forestry University, Kunming, 650224, \\ China; \\ ${ }^{2}$ City college, Kunming University of Science and Technology, Kunming, 650093, China; 3. Kunming \\ Institute of Precious Metals, Kunming, 650106, China. \\ *E-mail: wyuan88@126.com, kmust_welding@163.com, chz@ipm.com.cn
}

doi: $10.20964 / 2021.07 .13$

Received: 9 March 2021 / Accepted: 18 april 2021 / Published: 31 May 2021

\begin{abstract}
Tantalum (Ta) coatings have been widely used as a corrosion-resistant material in the aerospace, weapon equipment, and nuclear industries. However, the widespread use of these coatings is hindered mainly by selective corrosion. In this work, the selective corrosion of Ta coatings is reduced via anodic oxidation. The microstructure and thickness of the coatings were evaluated through scanning electron microscopy (SEM) and X-ray photoelectron spectroscopy (XPS) depth profiles. Moreover, XPS was also used to determine the valence state and surface composition of the coatings. Furthermore, the corrosionresistance behavior of the coating was investigated using an electrochemical workstation. The results revealed that the oxide film on the surface of the coating was still $\mathrm{Ta}_{2} \mathrm{O}_{5}$ after anodization, and the film thickness (i.e., $150 \mathrm{~nm}$ ) was approximately five times greater than that of the natural oxide. Furthermore, the anodic oxidation process reduced the formation of an island structure, improved the compactness of the Ta coating, and reduced chloride ion transport. More importantly, the corrosion current density of the Oxide/Ta/Mo (anodic oxidation) coating decreased by $26.47 \%$ (from $0.034 \mathrm{~A} \cdot \mathrm{cm}^{-2}$ to $0.025 \mathrm{~A} \cdot \mathrm{cm}^{-2}$ ) and the self-corrosion potential increased by $36.84 \%$ (from $-0.38 \mathrm{~V}$ to $-0.24 \mathrm{~V}$ ). This work can serve as a reference for improving the corrosion resistance of Ta coatings.
\end{abstract}

Keywords: tantalum coating; anodic oxidation; corrosion resistance; selective corrosion

\section{$\underline{\text { FULL TEXT }}$}

(C) 2021 The Authors. Published by ESG (www.electrochemsci.org). This article is an open access article distributed under the terms and conditions of the Creative Commons Attribution license (http://creativecommons.org/licenses/by/4.0/). 